\title{
Cherry Picking or Depth-Oriented Strategic Investing? Evidence from SRI Activity
}

\author{
Angeloantonio Russo ${ }^{1}$, Massimo Mariani ${ }^{1} \&$ Francesco Perrini ${ }^{1}$ \\ ${ }^{1}$ Department of Management, LUM University, Italy \\ Correspondence: Angeloantonio Russo, Department of Management, LUM University, Italy. E-mail: \\ russo@lum.it
}

Received: September 23, 2016

Accepted: October 11, $2016 \quad$ Online Published: October 27, 2016

doi:10.5539/ijbm.v11n11p13

URL: http://dx.doi.org/10.5539/ijbm.v11n11p13

\begin{abstract}
Today, socially responsible investing (SRI) represents the youngest financial-services industry that investors can exploit to implement their investment strategies. Although literature in this field is growing, additional research is needed to disentangle the factors affecting the performance of SRI funds. This paper focuses on the analysis of the influence that the depth of investment strategy by SRI funds may have on the investment performance, whereas larger SRI funds have a stronger capacity to address their investment choices. We used a sample of 149 USA SRI funds referring to the Social Investment Forum (SIF) Foundation in the period 2005-2010. We found that depth of investment strategy decreases the capacity of large SRI funds to reach positive financial returns if a broad sustainability investment strategy is pursued. On the other hand, SRI funds able to focus the attention on specific environmental, social, governance, or product criteria do increase their capacity to reach positive financial performance. This paper contributes to the existing literature by examining the depth of the sustainability investment strategy by SRI funds and investigating the moderating effect that peculiar investment strategies have on the well-known relation between size and performance of SRI funds.
\end{abstract}

Keywords: depth of investment strategy, ESG criteria, socially responsible investing, SRI funds, sustainability-oriented strategy

\section{Introduction}

Today, socially responsible investing (SRI) represents the youngest financial-services industry that investors can exploit to implement their investment strategies. SRI's modern roots originate from the 1960s (Schueth, 2003). Although literature in this field is growing, additional research is needed to explain which factors do affect the implementation of corporate sustainability (CS) strategies (Sparkes \& Cowton, 2004) by both firms and investors.

Relying on previous literature investigating the relationship between CS orientation and a firm's financial performance, this paper focuses on the analysis of the influence that the depth of the investment strategy by SRI funds may have on the investment performance. This study relies on the assumption that larger SRI funds should have a stronger capacity to address their investment choices, leading to a higher performance for their assets under management. In more detail, first the direct effect that size of SRI funds has on the financial performance is investigated; then, the moderating effect that a deep sustainability investment strategy by SRI funds can have on the above relation is tested. Both a broad and a narrow sustainability investment strategy by SRI funds are considered; the latter referring to the well-known attitude by SRI funds to focus on detailed environmental, social, governance (ESG), and product criteria while selecting their ethical target investments.

To test the hypotheses, a sample of USA SRI funds referring to the Social Investment Forum (SIF) Foundation in the period 2005-2010 has been used. The final sample included 149 SRI funds. In this study, firm performance is measured in terms of financial return provided by the SRI funds; both a short- and long-term perspective have been considered for financial returns. Size of SRI funds is measured through the total amount of assets under management by each fund. Last, sustainability investment strategy is measured through the typical classification of ESG and product criteria SRI funds typically use when selecting their target investments.

The results offer new light on the critical attention that SRI funds should posit on the deepness of their sustainability investment strategies while searching for positive financial performance. Surprisingly, we found 
that a broad sustainability investment strategy implemented by large SRI funds decreases their financial returns. On the other hand, SRI funds able to focus the attention on specific ESG or product criteria do increase their capacity to reach positive financial performance.

\section{Theoretical Background and Hypotheses}

\subsection{SRI Funds Investment Strategy}

In recent years, firms are increasing their investments in sustainable projects in order to bolster their reputations, thereby protecting their social licenses to operate. However, any investment a firm makes must also be profit oriented. Furthermore, the relationships among CS, reputation, and firm value must be analysed in order to justify the way firms manage their relationships with specific stakeholders, such as those in the market for control. Furthermore, those firms that were the early leaders in the sustainability arena are experiencing a kind of "Red Queen" effect (Robinson et al., 2011), as they need to continually find ways to differentiate themselves (Harwood et al., 2011; Russo \& Mariani, 2013).

The above context represents the conventional competitive arena in which SRI funds do pursue their investment activity, adopting a specific selection and investment process. In more detail, SRI funds refer to terms such as CS, corporate social responsibility (CSR), and sustainable development, which relate to the triple bottom line in which corporations focus on economic, social, and environmental values (Elkington, 1997). Shifting the focus on the firm perspective, inclusion in SRI portfolios can be one way for a firm to signal commitment to sustainability. SRI funds are important because they are external investors serving as an information intermediary between a firm and its stakeholders. SRI funds make objective, neutral, professional assessments of each company's strategic and sustainability activity (Dubbink et al., 2008).

Generally speaking, SRI investment should follow the theoretical framework referring to the lifecycle of sustainable investments. The lifecycle of sustainable investments is based on the proposition that socio-cultural, educational, economic, technical and climatic factors combine to form complex cause-effect patterns that affect the effectiveness of sustainable projects in communities (Parnell \& Seemann, 2005).

Today, SRI funds are generally aligned in implementing a selection process that is based on ESG and product criteria; the latter referring to product and industry characteristics through which SRI funds decide to invest or not. As an example, consider the negative screening activity implemented by SRI funds, which allows SRI funds to exclude from their portfolio all the products referring to animal testing, alcohol, defence and weapons, gambling, and tobacco activities. Therefore, in the following of this study, ESG and product criteria will be referred to as the bases of a sustainability investment strategy by SRI funds.

\subsection{Hypotheses}

Thus far, little research has attempted to address which are the factors affecting SRI performance. As of today, many studies have investigated the financial performance of SRI funds; moreover, controversial evidence does exist in the field of sustainable finance highlighting a superior performance by SRIs compared to the so called traditional investments. Very few studies have focused on the factors affecting the financial performance of SRI funds. Barnett and Salomon (2006) measure how screening intensity affects the financial performance of SRI funds. They find a curvilinear relationship between screening intensity, measured by the number of screening criteria, and financial performance. Renneboog, Ter Horst, and Zhang (2008) examine the impact of the screening activity on risk-adjusted returns and risk loading. They show that the number of social screens significantly reduces financial performance, while the number of ethical screens, the number of sin screens, or the number of environmental screens does not have any significant impact. Other studies point more attention on the systematic risk related to SRI fund performance. Lee, Humphrey, Benson and Ahn (2010) confirm that the number of screens negatively impacts performance, but also results in lower systematic risk. Humphrey and Lee (2012) provide a weak evidence that screening intensity increases (instead of decreases) risk-adjusted performance. Martì-Ballester (2015) analyses investor reactions to ethical screening by pension plan managers. While the results indicate that investors/consumers prefer traditional or solidarity pension plans to ethical pension plans, the research does not focus on the types of ESG criteria adopted by ethical pension plan managers, as well as on the weight given to each of these criteria for selecting the stock of the firms in their portfolios that could influence in the investors' behaviour.

Based on the above presented literature, this paper contributes to the debate moving from the "when does it pay to be good?" question (King \& Lenox, 2001) to the "why does it pay to be good?" question (Pogutz et al., 2010). The rationale behind is that investors having a deeper investment strategy in selecting their target alternatives experience a higher performance, due to the higher capacity of investment analysis. Therefore, more attention is 
required to untangle the factors affecting the relationship between depth of an investment strategy and SRI performance.

This paper first aims at investigating the influence that a deeper investment strategy by SRI funds may have on the investment performance. In particular, size expressed as assets under management is investigated as a first factor driving SRI funds toward a stronger capacity to address their investment choices, leading to highest performance. Although literature does exist on the relation between traditional fund performance and the size of assets under management (Chen et al., 2004; Indro et al., 1999), additional work is required to investigate the peculiarities of the investment strategy by SRI funds and how those peculiarities affect the above relation. Therefore, a first hypothesis rises on the relationship between size of the assets under management and the SRI performance as follows:

Hypothesis 1: A positive relationship does exist between the size of assets under management and the SRI performance

In a second step, depth of investment strategy by SRI funds is investigated since it might contribute to highest performances. Benson et al. (2006) suggest that SRI funds typically act as "stock pickers", therefore having a stronger capacity to identify best performer investments; that is basically due to the more restricted investment universe in which they operate, which in turn allows them to developed detailed competences in the investment process. Kempf and Osthoff (2007) investigate whether investors applying socially responsible screens when building their stock portfolios can increase their performance by incorporating such screens into their investment process. They find the maximum abnormal returns are reached when investors employ the best in-class screening approach, use a combination of several socially responsible screens at the same time, and restrict themselves to stocks with extreme socially responsible ratings. Finally, Capelle-Blancard and Monjon (2014) examine whether the financial performances of SRI funds are related to the features of the screening process. They find that financial performance is hurt by the exclusion of non-socially responsible stocks, but this initial negative effect is partly offset as the number of screens increases. Moreover, they do not find a clear evidence of whether one of the ESG factors exerts more influence than the others, therefore suggesting that these issues need further analysis.

Based on a resource perspective, largest SRI funds do hold the resources and competences to run detailed investment analysis that reduce the investment risk, which in turn should means higher performances. Therefore, a second hypothesis follows:

Hypothesis 2: The relationship between the size of assets under management and the SRI performance is moderated by the depth of the investment strategy. Specifically, as depth of the investment strategy increases, SRI funds with a larger amount of assets under management show higher financial performance.

Finally, in order to contribute to the comprehension of the above phenomenon, the ESG and product characteristics of the investment strategy by SRI funds are considered. Based on a triple-bottom line perspective (Elkington, 1997), the ESG and product characteristics of a sustainable investment strategy are investigated as moderating factors of the above relationship between size of assets under management and SRI fund performance. Therefore, a last set of hypotheses follows:

Hypothesis 3: The relationship between the size of assets under management and the SRI performance is moderated by the depth of the investment strategy, which focuses on:

(3a) environmental characteristics of the portfolio under management;

(3b) social characteristics of the portfolio under management;

(3c) governance characteristics of the portfolio under management;

(3d) product characteristics of the portfolio under management.

Specifically, as depth of the investment strategy increases which focuses on environmental, social, governance, and product characteristics, SRI funds with a larger amount of assets under management show higher financial performance.

\section{Methodology}

\subsection{Sample and Analysis}

This study aims at investigating if specific factors, such as size of assets under management and depth of investment strategies by SRI funds, can influence the investment performance. To test the hypotheses, a sample of U.S. SRI funds referring to the Social Investment Forum (SIF) Foundation in the period 2005-2010 is used. 
The population taken into consideration included 151 U.S. SRI funds; having excluded 2 funds due to lack of data, the final sample included 149 U.S. SRI funds. The use of a single-country sample has been based on a multiple rationale: first, a single-country sample is focused on a specific cultural context, which allow us to avoid the influence of different cultural dimensions on the investment strategy by each fund included in the analysis, as well as the influence of different financial effects on the investment performance (Fulop et al., 2000); second, the U.S. funds presented a higher access to financial and strategic data and information necessary for analysis; last but not least, although SRI funds have been gaining worldwide popularity, the USA is clearly the most developed market for this type of investments (Cortez et al., 2012). In the USA, as of 2012 the assets engaged in SRI practice represent 11.3 percent of the $\$ 33.3$ trillion in total assets under management; in the period 1995-2012, the SRI universe has increased 486 percent, while the broader universe of assets under professional management in the USA has grown 376 percent (SIF, 2012).

SRI Funds included in the sample have been analysed and classified based on peculiarities of SRI funds by type of investment (i.e., balanced, bond, equity large cap, equity mid-small cap, equity specialty, and international/global SRI funds) and capitalization, which on average is 345 million dollars.

In order to test the hypotheses, an Ordinary Least Square (OLS) regression model has been estimated due to the nature of the dependent variable. Several regression models have been run, each including the different predictors and moderating variables. In each model, a hierarchical regression approach to test our hypotheses has been run. In other words, the control variables were entered into the regression first, after which the predictors were added.

We checked for potential multicollinearity in our independent variables in two ways. First, we assessed the variance inflation factors (VIF) by running OLS regressions and found that none of the values exceeded the accepted maximum of 10 (Neter et al., 1990). Second, when running our models, we systematically deleted one independent variable at a time, and then checked whether the deletion changed the sign or significance level of any of the key independent variables (Hillman et al., 2007). None of the signs or significance levels was affected, supporting the conclusion that multicollinearity was not a problem. Moreover, we checked for heteroskedasticity using the Breusch-Pagan test (Breusch \& Pagan, 1979). The test rejected the null hypothesis of heteroskedasticity, providing evidence that heteroskedasticity was not a problem in our dataset.

Data and information related to the variables included in the analysis were collected from the Social Investment Forum (SIF) Foundation that was publicly available and integrated with proprietary databases on economic and financial performance, such as the Datastream and Bloomberg databases.

\subsection{The Dependent Variable: Financial Performance}

We measure the financial performance of SRI funds through the average return gained by each fund in a given time $t$ (Cortez et al., 2012; Yu, 2014). In order to avoid an endogeneity problem, a time-lag between the dependent variable and the predictors was included. More specifically, a twofold perspective has been used in the analysis to investigate the effect of predictors over the dependent variable both in the short- and long-term period. In more detail, we considered a one-year average return $(t+1)$ of the SRI funds to measure the short-term financial performance and a five-year average return $(t+5)$ of the SRI funds to measure the long-term financial performance.

\subsection{The Predictor}

The first main hypothesis investigated in this study suggests that size of SRI funds does affect the performance of SRI investments. To measure size of SRI funds we referred to total amount of assets under management held by each SRI fund in the sample. Assets under management are typically used as a measure of size of SRI (and traditional) investments (Benijts, 2010). In this study, we measured the log of assets under management in order to reduce the variance within the variable. In absolute terms, assets under management in our sample ranged from 1.7 to 2,884 million dollar.

\subsection{The Moderating Effects}

To test the moderating effect of depth of investment strategy over the relationship between size and performance of SRI investments, several steps have been taken into account to build different measures of depth of investment strategy. First, the 14 different ESG and Product criteria through which SRI funds assess their investments have been considered. A general framework with classes and criteria is presented in Figure 1. 


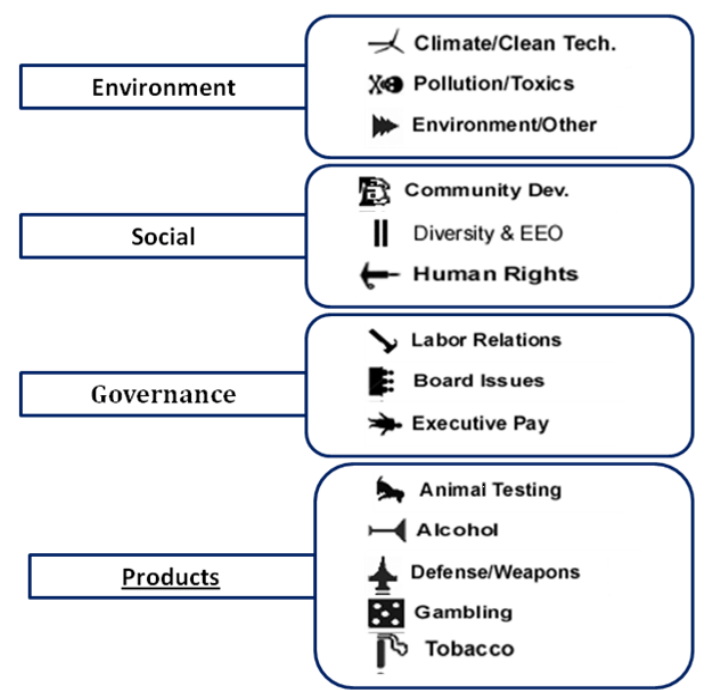

Figure 1. SRI Investment strategy by classes and criteria

After the criteria have been identified, each has been ranked with a score ranging from 0 to 3 . Therefore, a categorical variable has been created to measure the depth of investment strategy and ranked 0 if the specific criterion has not been considered 1 if the criteria are partially considered identifying a so called "restricted investment" (i.e., investments where a limited amount of gross return are expected and allowed to be related to non-ethical activities - e.g., only $10 \%$ of gross returns can be derived from investments in defence/weapons industry); 2 if a negative screening has been applied based on a specific criterion; and 3 if the criteria have been fully used to identify an ethical investment based on the highest degree of deepness of the investment strategy. The use of items scored on a "present/absent" basis has already been observed and raises no specific methodological issue (Barrett, 1976). Moreover, in line with relevant literature on the index-scoring approach, the items can be weighted (Cooke, 1989) or unweighted (Ahmed \& Nicholls, 1994). However, while many studies raise this issue, there is no one dominant practice. In this study, the scores for the ESG criteria were equally weighted in order to calculate the overall score for each SRI fund. After the categorical variable has been measured a compounded average has been computed, weighting the 4 different classes depending on the number of criteria in each class. Finally, the same procedure has been used to compute 4 different categorical variables, one for each of the 4 classes of investment strategy: environmental depth, social depth, governance depth, and product depth.

\subsection{Control Variables}

Several control variables were included in the regression models that might influence the performance of SRI investments. A first control variable has been considered to check for the experience effect. In particular, SRI funds included in the analysis have been classified based on their age. Therefore, 3 dummy variables have been computed: a dummy variable has been ranked with 1 if the SRI fund was created in the period 2000-2009, zero otherwise; a second dummy variable considered the SRI funds created in the period 1992-1999; last, SRI funds created in the period before 1992 have been included in a third dummy variable, which was omitted and considered as base-value. 
Table 1. Correlation matrix

\begin{tabular}{|c|c|c|c|c|c|c|c|c|c|c|c|c|c|c|c|c|c|c|c|c|}
\hline & Mean & SD & 1 & 2 & 3 & 4 & 5 & 6 & 7 & 8 & 9 & 10 & 11 & 12 & 13 & 14 & 15 & 16 & 17 & $18 \quad 19$ \\
\hline 1 Year: 2009-2000 & 0.45 & 0.25 & & & & & & & & & & & & & & & & & & \\
\hline 2 Year: 1999-1992 & 0.36 & 0.58 & $-0.78^{* * *}$ & & & & & & & & & & & & & & & & & \\
\hline 3 Year: 1992 & 0.19 & 0.30 & $-0.41^{* * *}$ & ${ }^{*}-0.23^{* * *}$ & & & & & & & & & & & & & & & & \\
\hline 4 Management fee & 0.74 & 0.45 & 0.10 & -0.07 & -0.06 & & & & & & & & & & & & & & & \\
\hline 5 Expense ratio & 1.44 & 0.68 & -0.11 & 0.10 & 0.03 & $0.61^{* * *}$ & & & & & & & & & & & & & & \\
\hline 6 Minimum account & 217.68 & 8407.88 & $80.20^{* *}$ & -0.08 & $-0.16^{*}$ & -0.11 & $-0.39^{* * *}$ & & & & & & & & & & & & & \\
\hline 7 Bond & 0.13 & 0.34 & $-0.14^{*}$ & $0.22^{* * *}$ & -0.07 & $-0.22^{* * *}$ & ${ }^{*}-0.26^{* * *}$ & * 0.07 & & & & & & & & & & & & \\
\hline 8 Balanced & 0.07 & 0.25 & $-0.26^{* * *}$ & ${ }^{*} 0.17^{* *}$ & $0.17^{* *}$ & -0.06 & 0.05 & -0.07 & $7-0.11$ & & & & & & & & & & & \\
\hline 9 Equity large cap & 0.30 & 0.46 & -0.09 & 0.10 & 0.01 & -0.11 & -0.15 & 0.06 & $-0.26^{* * *}$ & ${ }^{*}-0.17^{* *}$ & & & & & & & & & & \\
\hline $\begin{array}{l}\text { Equity mid-small } \\
\text { cap }\end{array}$ & 0.23 & 0.42 & 0.04 & $-0.19^{* *}$ & $0.17^{* *}$ & 0.10 & 0.11 & -0.01 & $1-0.21^{* * *}$ & * -0.14 & $-0.35^{* * *}$ & & & & & & & & & \\
\hline 11 Equity specialty & 0.10 & 0.30 & $0.23^{* * *}$ & $-0.17^{* *}$ & -0.11 & -0.09 & 0.07 & -0.14 & $4-0.13$ & -0.09 & $-0.21^{* * *}$ & ${ }^{*}-0.17^{* *}$ & & & & & & & & \\
\hline 12 International/global & 10.17 & 0.37 & $0.19^{* *}$ & -0.09 & $-0.16^{*}$ & $0.33^{* * *}$ & $0.21^{* *}$ & 0.05 & $-0.18^{* *}$ & -0.13 & $-0.31^{* * *}$ & $-0.25^{* * *}$ & * -0.15 & & & & & & & \\
\hline $13 \begin{array}{l}\text { Depth invest. } \\
\text { strategy }\end{array}$ & 1.76 & 0.58 & -0.06 & 0.08 & -0.03 & -0.16 & -0.11 & 0.02 & -0.07 & -0.07 & $0.31^{* * *}$ & -0.00 & -0.08 & $8-0.21^{* *}$ & & & & & & \\
\hline 14 Depth Environment & t 2.25 & 0.41 & -0.10 & 0.12 & -0.06 & 0.05 & $0.28^{* * *}$ & -0.06 & $6-0.12$ & 0.14 & -0.01 & -0.11 & 0.11 & 0.06 & $0.30^{* * *}$ & & & & & \\
\hline 15 Depth Social & 2.10 & 0.27 & -0.02 & 0.03 & -0.02 & $-0.17^{* *}$ & $-0.15^{*}$ & 0.09 & -0.05 & 0.05 & $0.31^{* * *}$ & -0.05 & -0.11 & -0.22 & $0.89^{* * *}$ & $0.28^{* * *}$ & & & & \\
\hline 16 Depth Governance & 2.02 & 0.38 & -0.13 & 0.12 & -0.00 & -0.08 & 0.09 & -0.05 & $5-0.15^{*}$ & -0.00 & 0.12 & 0.02 & -0.00 & -0.03 & $0.80^{* * *}$ & $0.54^{* * *}$ & $0.59^{* * *}$ & & & \\
\hline 17 Depth Product & 1.10 & 0.20 & 0.04 & 0.02 & -0.07 & -0.1 & $-0.24^{* * *}$ & * 0.01 & 0.02 & $-0.22^{* * *}$ & ${ }^{*} 0.35^{* * *}$ & -0.01 & -0.04 & $4-0.26^{* * *}$ & ${ }^{* *} 0.58^{* * *}$ & ${ }^{*}-0.21^{* * *}$ & ${ }^{*} 0.49^{* * *}$ & * 0.06 & & \\
\hline 19 Performance $t+1$ & 5.22 & 7.35 & -0.06 & 0.06 & -0.01 & $0.26^{* * *}$ & 0.03 & -0.09 & $90.21^{* * *}$ & -0.01 & 0.10 & 0.16 & 0.05 & $-0.51^{* * *}$ & ${ }^{* *} 0.25^{* * *}$ & 0.01 & $0.21^{* * *}$ & * 0.08 & $0.32^{* * *}$ & * 0.07 \\
\hline 20 Performance $t+5$ & -0.34 & 3.42 & -0.02 & 0.10 & -0.10 & $-0.32^{* * *}$ & ${ }^{*}-0.49^{* * *}$ & * 0.06 & $0.70^{* * *}$ & 0.03 & $-0.28^{* * *}$ & ${ }^{*}-0.32^{* * *}$ & ${ }^{*} 0.11$ & -0.12 & -0.06 & $-0.31^{* * *}$ & ${ }^{*}-0.01$ & $-0.20^{*}$ & *0.09 & $0.170 .53^{* * *}$ \\
\hline
\end{tabular}

Notes. ${ }^{* * *} \mathrm{p}<0.01,{ }^{* *} \mathrm{p}<0.05,{ }^{*} \mathrm{p}<0.10 ; \mathrm{n}=149$.

Moreover, technical aspects related to the SRI fund management peculiarities have been controlled for. In details, the expense ratio has been considered, representing the ratio (expressed in percentage) of the total annual cost by the fund's total assets averaged over that year. The management fees have also been included in the analysis, representing the fees paid to the fund managers as part of the total cost for the investors participating the specific SRI fund. Moreover, the minimum account was checked for, representing the minimum ticket required to invest in a specific SRI fund; the log of the minimum account expressed in million dollars has been computed. Finally, the different typology of SRI fund has been included in the analysis; in particular, we computed six dummy variables, ranking the variable 1 if the SRI fund was in a specific category, zero otherwise. The dummy variables included in the analysis were Balanced (BL), Bond (BD), Equity Large Cap (EL), Equity Mid-Small Cap (EM), Equity Specialty (ES), and International/Global (IG).

\section{Results}

The results of the regressions performed in this study are summarized in the Tables 1, which presents the correlations between the variables included in the analysis, and Table 2, which offer the statistical results of the regression models. 
Table 2. Results for hypothesis tests: asset under management and depth investment strategy moderating effect

\begin{tabular}{|c|c|c|c|c|c|c|}
\hline & \multicolumn{2}{|c|}{$\begin{array}{l}\text { Model } 1 \\
\text { Control variables }\end{array}$} & \multicolumn{2}{|c|}{$\begin{array}{l}\text { Model } 2 \\
\text { Hypothesis } 1\end{array}$} & \multicolumn{2}{|c|}{$\begin{array}{l}\text { Model } 3 \\
\text { Hypothesis } 2\end{array}$} \\
\hline & $\mathrm{t}+1$ & $\mathrm{t}+5$ & $\mathrm{t}+1$ & $\mathrm{t}+5$ & $\mathrm{t}+1$ & $\mathrm{t}+5$ \\
\hline Constant & 5.959356 & 1.2207 & 5.9722 & 0.6992 & $2.2177^{* * *}$ & 1.1260 \\
\hline Year: 2009-2000 & -2.4740 & 0.3395 & -2.4725 & 0.2375 & -3.1675 & 0.2996 \\
\hline Year: 1999-1992 & -1.7747 & 0.2267 & -1.7735 & 0.1577 & -1.8034 & 0.4318 \\
\hline Management fee & $10.712^{* * *}$ & $2.3891^{*}$ & $10.7123^{* * *}$ & $2.1584^{*}$ & $8.822^{* * *}$ & $2.0517^{*}$ \\
\hline Expense ratio & $-2.4712^{* *}$ & $-2.1709^{* * *}$ & $-2.4731^{* *}$ & $-2.0304^{* * *}$ & $-1.7374^{*}$ & $-1.9982^{* * *}$ \\
\hline Minimum account & -0.5340 & -0.3686 & -0.5349 & -0.3101 & -0.5277 & -0.2805 \\
\hline Balanced & (Omitted) & 1.8616 & $4.9127^{* *}$ & 1.8153 & (Omitted) & -0.4627 \\
\hline Bond & $4.9123^{* *}$ & $6.2884^{* * *}$ & (Omitted) & 6.0774 & $5.2646^{* *}$ & $3.4886^{* * *}$ \\
\hline Equity Large Cap & 0.3883 & -0.3024 & 0.3878 & -0.5018 & -0.4351 & $-3.2748^{* * *}$ \\
\hline Equity Mid-Small Cap & 0.9903 & -0.7005 & 0.9836 & 0.4554 & -0.6196 & $-3.2760^{* * *}$ \\
\hline Equity Specialty & 1.7171 & $2.6890^{*}$ & 1.7091 & $2.9367^{* *}$ & 0.8445 & (Omitted) \\
\hline International/Global & $-11.5502^{* * *}$ & (Omitted) & $-11.5557^{* * *}$ & (Omitted) & -10.8654 & $-2.3445^{*}$ \\
\hline Assets Under Management (AuM) & & & 0.0002 & $0.0011^{* *}$ & $0.0050^{* * *}$ & $0.0019^{*}$ \\
\hline Depth investment strategy & & & & & 4.5009 & 1.1889 \\
\hline AuM x Depth investment strategy & & & & & $-1.5773^{* * *}$ & -0.2986 \\
\hline $\mathrm{R}^{2}$ & 0.5374 & 0.6779 & 0.5374 & 0.6965 & 0.6094 & 0.7104 \\
\hline $\mathrm{R}^{2}$ adjusted & 0.4957 & 0.6280 & 0.4915 & 0.6445 & 0.5635 & 0.6508 \\
\hline $\mathrm{F}$ & 12.88 & 13.59 & 11.71 & 13.39 & 13.26 & 11.92 \\
\hline $\mathrm{p}<$ & 0.0000 & 0.0000 & 0.0000 & 0.0000 & 0.0000 & 0.0000 \\
\hline
\end{tabular}

Notes. ${ }^{* * *} \mathrm{p}<0.01,{ }^{*} \mathrm{p}<0.05,{ }^{*} \mathrm{p}<0.10$.

Table 2 presents the results for hypothesis test related to hypothesis 1 and 2 (respectively, Model 2 and 3). Model 1 refers to the control variables, whereas predictors have not been included. Hypothesis 1 predicted a positive relationship between financial performance of SRI funds and size of assets under management. Results presented in Tables 2 show a positive $(r=0.0011)$ and strong statistically significant $(p<0.01)$ relationship if a long-term perspective is considered. Therefore, hypothesis 1 is supported if a long-term financial performance is taken into account.

Hypothesis 2 investigated the moderating effect that depth of an investment strategy can have on the above presented positive relationship between SRI financial performance and size of assets under management. Our results reveal (Model 3 in Table 2) that a deeper investment strategy based on sustainability criteria has a negative $(\mathrm{r}=-1.5773)$ and statistically strongly significant $(\mathrm{p}<0.01)$ moderating effect on the relationship between short-term SRI financial performance and assets under management. A statistically non-significant effect has been found in the long-term run. Therefore, hypothesis 2 is not supported.

Depth Investment Strategy

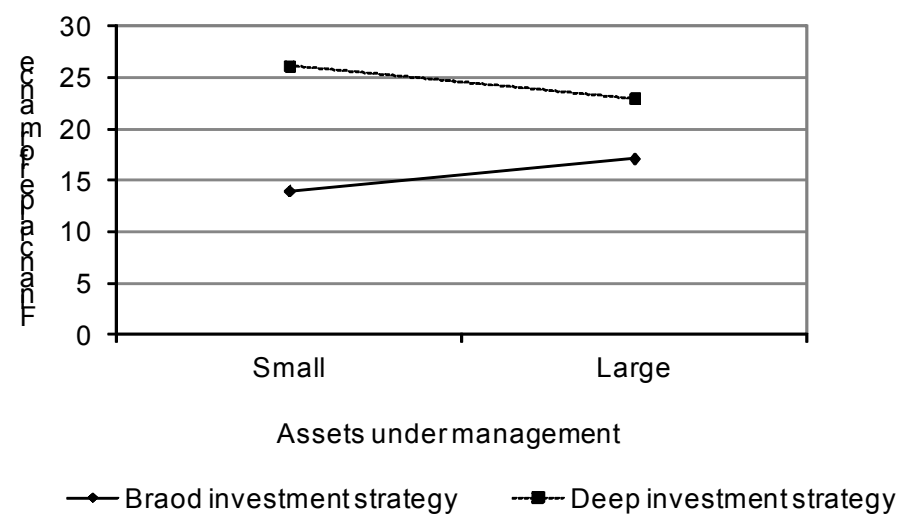

Figure 2. Interaction between assets under management and depth investment strategy on financial performance 
To seek deeper insights, into the particular nature of the factors affecting the financial performance of SRI funds, we plotted the interactions between the amount of assets under management and deepness of investment strategy on financial performance. We plotted this relationship for one standard deviation above and below the average assets under management values of our sample. Figure 2 shows that larger SRI funds experiences a decrease in financial performance as deepness of investment strategy increases.

Results presented in Table 3 refer to Hypotheses 3a, 3b, 3c, and 3d. In particular, Hypothesis $3 a$ predicted the moderating effect that depth of an environmental-based investment strategy has on the positive relationship between size of assets under management and SRI fund performance.

Our results provide evidence of a positive $(r=3.8601)$ and statistically significant $(\mathrm{p}<0.01)$ relationship when considering a short-term perspective. The results are strongly significant therefore supporting Hypothesis $3 \mathrm{a}$. Surprisingly, non-significant results emerged with regard to a long-term perspective.

While considering the moderating effect of depth of a social-based investment strategy, we found same results. A positive $(\mathrm{r}=3.0904)$ and statistically significant $(\mathrm{p}<0.05)$ relationship emerged in the short-run. Non-significant results are provided in the long-term perspective. Therefore, embracing a short-term perspective, the results are significant and Hypothesis $3 \mathrm{~b}$ is supported in the short-term.

Hypothesis $3 \mathrm{c}$ predicted a positive moderating effect of depth of a governance-based investment strategy over the relationship between size of assets under management and SRI fund performance. Again, the results provided a positive $(\mathrm{r}=3.1675)$ and statistically significant $(\mathrm{p}<0.01)$ relationship in the short-term, while no-significant results emerged considering the long-term performance. Therefore, hypothesis $3 \mathrm{c}$ is supported in the short-term.

Table 3. Results for hypothesis tests: moderating effect of depth investment strategy focused on environment, social, governance, and product criteria

\begin{tabular}{|c|c|c|c|c|c|c|c|c|}
\hline & \multirow{2}{*}{\multicolumn{2}{|c|}{$\begin{array}{l}\text { Model } 4 \\
\text { Hypothesis } 3 \mathrm{a}\end{array}$}} & \multirow{2}{*}{\multicolumn{2}{|c|}{$\begin{array}{l}\text { Model } 4 \\
\text { Hypothesis } 3 b\end{array}$}} & \multirow{2}{*}{\multicolumn{2}{|c|}{$\begin{array}{l}\text { Model } 4 \\
\text { Hypothesis 3c }\end{array}$}} & \multirow{2}{*}{\multicolumn{2}{|c|}{$\begin{array}{l}\text { Model } 4 \\
\text { Hypothesis 3d }\end{array}$}} \\
\hline & & & & & & & & \\
\hline & $\mathrm{t}+1$ & $\mathrm{t}+5$ & $\mathrm{t}+1$ & $\mathrm{t}+5$ & $\mathrm{t}+1$ & $\mathrm{t}+5$ & $\mathrm{t}+1$ & $\mathrm{t}+5$ \\
\hline Constant & 5.4540 & 2.3689 & 3.5801 & -1.5538 & 4.5715 & 0.8038 & 2.8713 & -1.3671 \\
\hline Year: 2009-2000 & -2.9677 & -0.5462 & -2.6661 & 0.7833 & -2.7501 & 0.1651 & -5.0121 & -0.5524 \\
\hline Year: 1999-1992 & -1.6606 & 0.7626 & -1.4299 & 0.9041 & -1.7042 & 0.0313 & -3.5036 & -0.5982 \\
\hline Management fee & $8.3903^{* * *}$ & 1.5098 & $9.2427^{* * *}$ & $2.1014^{*}$ & $10.0742^{* * *}$ & $2.2168^{* * *}$ & $7.5753^{* * *}$ & 1.5288 \\
\hline Expense ratio & $-2.3050^{* *}$ & $-1.5461^{* * *}$ & $-1.9286^{* *}$ & $-1.9939^{* * *}$ & $-2.2168^{* *}$ & -2.0177 & -1.2301 & $-1.5348^{* * *}$ \\
\hline Minimum account & -0.5463 & -0.1366 & -0.5714 & 0.2831 & -0.5683 & -0.3233 & 0.3631 & -0.0669 \\
\hline Balanced & (Omitted) & 1.8153 & (Omitted) & 1.4748 & (Omitted) & 1.7827 & (Omitted) & $2.1664^{*}$ \\
\hline Bond & $5.7038^{* * *}$ & $5.9762^{* * *}$ & 5.4682 & $5.6250^{* * *}$ & $4.8482^{* *}$ & $6.1073^{* * *}$ & $5.1894^{* *}$ & $5.9039^{* * *}$ \\
\hline Equity Large Cap & 0.3583 & -0.6711 & 0.0612 & -1.0691 & -0.1832 & -0.5957 & -0.7158 & -0.9771 \\
\hline Equity Mid-Small Cap & 0.1291 & -1.0436 & 0.3895 & -0.8069 & -0.7755 & $0.8482^{*}$ & -0.3765 & -0.9124 \\
\hline Equity Specialty & -1.0358 & 2.4215 & 1.71187 & $2.3521^{*}$ & 0.5178 & 2.5502 & $0.3526^{* * *}$ & $2.4979^{*}$ \\
\hline International/Global & $-11.0915^{* * *}$ & (Omitted) & $-10.7046^{* * *}$ & (Omitted) & $-12.1315^{* * *}$ & (Omitted) & -9.9735 & (Omitted) \\
\hline Assets Under Management (AuM) & $0.0039^{* * *}$ & $0.0014^{*}$ & $0.0036^{* *}$ & $0.0018^{* *}$ & $0.0032^{*}$ & $0.0016^{*}$ & $0.0053^{* * *}$ & $0.0017^{* *}$ \\
\hline Depth environment & $9.3702^{* * *}$ & -0.3902 & & & & & & \\
\hline AuM x Depth environment & $3.8601^{* * *}$ & -0.3882 & & & & & & \\
\hline Depth social & & & $8.1838^{* * *}$ & 2.9028 & & & & \\
\hline AuM x Depth social & & & $3.0904^{* *}$ & -0.6331 & & & & \\
\hline Depth governance & & & & & $8.3393^{* * *}$ & 1.2658 & & \\
\hline AuM x Depth governance & & & & & $3.1675^{* * *}$ & -0.5675 & & \\
\hline Depth product & & & & & & & $15.2327^{* * *}$ & 3.14477 \\
\hline AuM x Depth product & & & & & & & $5.1868^{* * *}$ & -0.5983 \\
\hline $\mathrm{R}^{2}$ & 0.5945 & 0.7229 & 0.5764 & 0.7141 & 0.5851 & 0.6991 & 0.6221 & 0.7183 \\
\hline $\mathrm{R}^{2}$ adjusted & 0.5468 & 0.6658 & 0.5265 & 0.6552 & 0.5363 & 0.6371 & 0.5777 & 0.6603 \\
\hline $\mathrm{F}$ & 12.46 & 12.67 & 11.57 & 12.13 & 11.99 & 11.28 & 13.99 & 12.38 \\
\hline $\mathrm{p}<$ & 0.0000 & 0.0000 & 0.0000 & 0.0000 & 0.0000 & 0.0000 & 0.0000 & 0.0000 \\
\hline
\end{tabular}


Hypothesis $3 \mathrm{~d}$ investigated the positive moderating effect of depth of a product-based investment strategy on the relationship between size of assets under management and SRI fund performance. Again, the results provided a positive $(\mathrm{r}=5.1868)$ and statistically significant $(\mathrm{p}<0.01)$ relationship in the short-term, while no-significant results emerged considering the long-term performance. Also Hypothesis $3 \mathrm{~d}$ is supported over the short-run.

Once again, we plotted the interactions between the amount of assets under management and deepness of ESG and product criteria on financial performance. We plotted these relationships for one standard deviation above and below the average assets under management values of our sample. Figure 3 shows that larger SRI funds experiences an increase in short-term financial performance as depth of environmental-, social-, governance-, and product-based investment strategy increases.

Depth Environment (a)

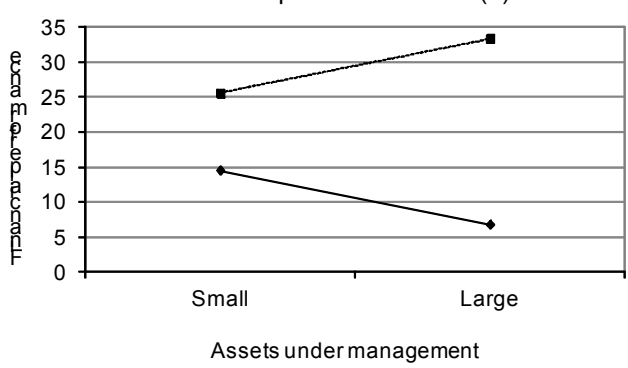

$\rightarrow-$ Braod investment strategy $\rightarrow-$ Deep investment strategy
Depth Social (b)

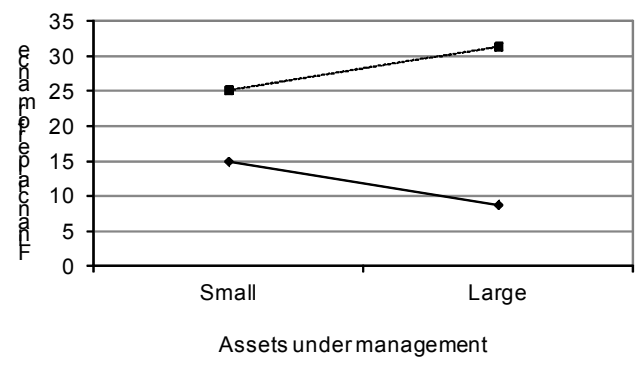

$\rightarrow$ Braod investment strategy $\rightarrow$-Deep investment strategy
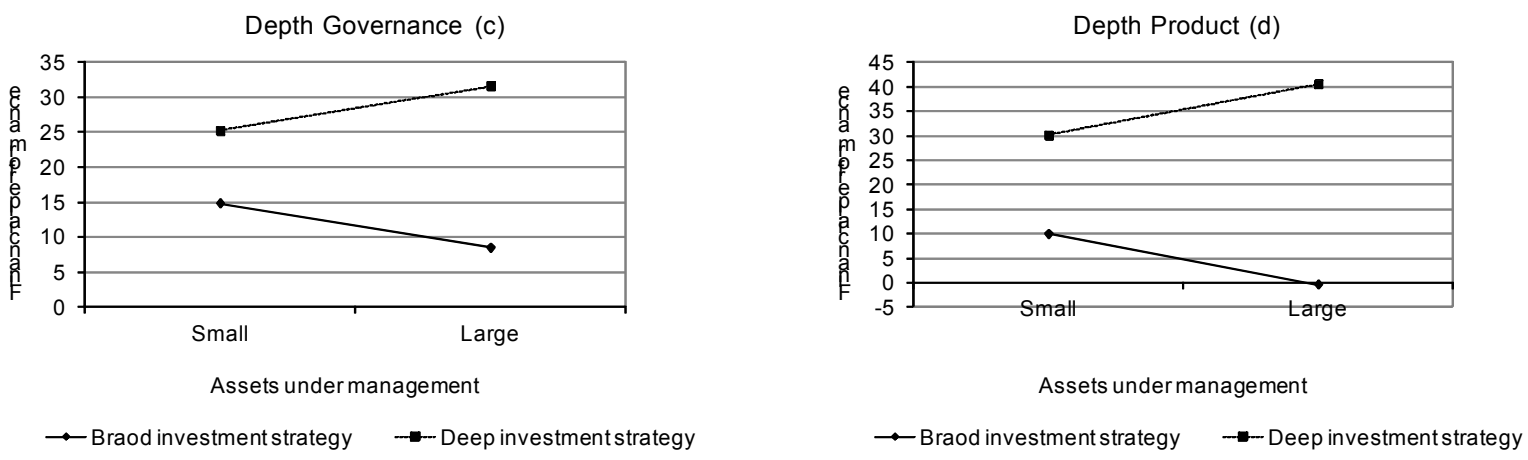

Figure 3. Effects of Interaction between assets under management and depth environment (a), social (b), governance (c), and product (d) strategy on financial performance

\section{Discussion and Conclusions}

This study tested the influence of specific factors on the financial performance of SRI funds in both a short- and long-term perspective. Literature in the field of SRI has rarely focused on the drivers of SRI fund performance. This paper is a first attempt to fill this gap by investigating the moderating effect that depth of a sustainability-oriented investment strategy has on the relationship between size and the financial return of SRI funds.

In particular, we found that size of SRI funds can influence the capacity to gain higher positive financial returns. Moreover, the results offer empirical evidence of the critical attention required by SRI funds to the depth of their sustainability investment strategies while searching for positive financial performance. Surprisingly, we found that depth of sustainability investment strategy decreases the capacity of large SRI funds to reach positive financial returns if a broad sustainability investment strategy is pursued. On the other hand, SRI funds able to focus the attention on specific ESG or product criteria do increase their capacity to reach positive financial performance. The results are important for researchers and practitioners interested in both the strategic and ethical peculiarities of SRI, which are therefore discussed in detail. 


\subsection{The Influence of Size of SRI Funds on Financial Performance}

First, we investigated the direct influence that size of SRI funds has on the financial performance both in a shortand long-term perspective. Our results confirm that largest SRI funds are those revealing highest performance. Relying on a resource-based perspective, SRI funds with a larger amount of assets under management do hold a bundle of resources that guarantee a higher capacity of analysis. Moreover, larger SRI funds are characterized by a higher degree of diversification, which in turns provides a lower financial and strategic risk. All these factors do explain the higher financial return that a larger SRI fund reach compared with smallest one.

Considering the ethical implications of our results, we argue that a larger amount of assets under management does mean higher capacity by the institutional investor to support the ethical investment and growth of target companies (Russo \& Perrini, 2006). Therefore, the ethical relevance of our result is even important if we consider the diffusion of sustainability-oriented practices the target companies are supposed to emphasize by definition after the investment is completed by the SRI fund. Investing in sustainability-oriented projects is a way to multiply the positive impact of the social and/or environmental practices implemented by the target company. Second, largest SRI funds do hold more resources through which the best projects are selected: therefore, it does come out that a deepest analysis of the ethical characteristics of the target project is ensured, minimizing the probability of what can be defined as an ethical default.

\subsection{The Moderating Effect of Deepness of a Sustainability Investment Strategy}

Considering the depth of a sustainability investment strategy as a whole, we found a first surprising result. Despite the positive moderating effect of depth of a sustainability-oriented investment strategy assumed in our hypothesis, we found a broad sustainability-oriented investment strategy decreases the positive relationship between the amount of assets under management and the financial return of SRI funds. That means, although larger SRI funds reach highest financial returns, those SRI funds that are characterized by a higher degree of deepness of their sustainability strategy reveal a lower financial performance at least in the short-term.

This result is controversial. On the one hand, depth of investment strategy is supposed to surround the capacity by the investor to clearly identify opportunities and threats related to a target project. On the other hand, a first explanation of this result can refer to the lower degree of focalization that a broad sustainability-oriented investment strategy implies for institutional investors. Managers in charge of the selection process related to the institutional activity by SRI funds should be therefore aware of taking in due care the opportunity for specialization while selecting the sustainability criteria that fit better with the target project. Although depth of a sustainability investment strategy requires a higher investment of resources, large firms should carefully identify those resources involved in the sustainability investment process.

A second explanation can refer to the empirical observation of the SRI competitive arena. Our result suggests the opportunity for rethinking the complex framework behind an SRI investment strategy. If the maximum financial return on investment is the ultimate objective of a SRI decision, such a target objective is not necessarily a prerogative by large SRI funds. More attention therefore has to be given to the selection criteria characterizing the sustainability investment process. Despite the size of assets under management, which in turn directly refer to the capacity by the SRI fund to exploit its resources and maximize the financial performance, large SRI funds do not necessarily reveal a higher capacity to identify and implement a deep sustainability investment strategy.

Shifting to an ethical explanation, our result emphasizes the opportunity for paying attention to the ethical implications of an SRI decision compared to its financial implications. Although large SRI funds are supposed to provide the investors with a higher degree of trustworthiness, the latter do not necessarily find a counterpart in a positive financial return. This result is interesting itself if we assume that investors participating SRI funds are able to give higher priority to ethical returns instead of financial returns. Of course, the above assumption is supposed to be accepted by definition, but our result is interesting in order to underline the opportunity of prioritizing ethical versus financial performance while selecting the target projects. Therefore, evidence provided in this study underlines that it is not about how much SRI funds earn in terms of financial returns, but it should be more about how returns are gained and sustained in the short-term through a specific sustainability investment strategy.

Moving to the depth of a focused sustainability investment strategy by SRI funds, the results provide evidence that depth of sustainability criteria is relevant in the short-term. Large SRI funds do hold the resources and competences to deeply select the target investments based on specific sustainability criterion. Therefore, a focused sustainability-oriented strategy minimizes the riskiness of the selection process that in turn reveals higher financial returns. As an example, consider a large SRI fund whose investment strategy focuses specifically on deep environmental criteria for the selection of target investments. Deep environmental criteria 
help contribute to increase the positive financial performance the large SRI fund reaches in short-term. Same considerations are provided by the results if social, governance, or product criteria are considered. Surprisingly, the results do not confirm the moderating positive effect of ESG and product criteria over the long-term. On the one hand, this result is aligned with what we found for a broader sustainability investment strategy. It suggests that the definition and implementation of a selection process by large SRI fund does have relevance in influencing the financial performance in the short-term; additional factors might therefore influence the financial returns in the long-term, which might depend on exogenous features.

Shifting to the ethical implications of our result, we can argue that target sustainable projects do benefit from a large SRI fund investment if the latter do have the resources and competences to run a deep and focused sustainability investment strategy. Of course, large SRI funds are those that by definition are supposed to potentially invest a higher amount of resources into a specific project. Therefore, large SRI funds willing to increase their short-term financial performance should centre their investment strategy on the bases of a detailed and focused sustainability criterion (i.e., ESG or product). Adopting a selection process perspective, this result highlights a higher capacity to identify the best ethical and organizational fit between target projects and sustainability investment strategy by large SRI funds.

\subsection{Conclusions, Limits and Cues for Future Research}

This study highlights several possibilities for additional investigations into the nature and structure of SRI, with special emphasis on the factors that really determine the well-known higher financial performance by SRI funds compared to the so called traditional funds. The availability of a deepest framework for measuring the quality of a good SRI sustainability investment strategy could be useful in this regard. The results provided in this study are a first evidence of the additional work still required to understand why SRI funds do seem to guarantee a higher performance, and less risky investment for sustainability oriented investors as well as for traditional investors.

This study has limits of course, which in turn could be considered as cues for future research. First, the use of a different sample embracing a multi-cultural perspective could provide additional evidence. That means, cultural differences under the perspective of both the SRI fund and target projects can be considered as an additional moderator of the positive financial returns provided by SRI funds. Second, in this study we only use a financial performance measure to investigate the return provided by SRI funds. Using a broader performance perspective can provide additional insights for the debate. In particular, shifting from a financial to a sustainability performance can deeply improve our knowledge on the capacity by SRI funds to generate positive returns. Last, a panel analysis considering a larger investment time period can increase the statistical significance of the discussed results.

\section{References}

Ahmed, K., \& Nicholls, D. (1994). The Impact of Non-Financial Company Characteristics on Mandatory Disclosure Compliance in Developing Countries: The Case of Bangladesh. The International Journal of Accounting, 29, 62-77.

Barnett, M., \& Salomon, M. (2006). The curvilinear relationship between social responsibility and financial performance. Strategic Management Journal, 27, 1101-1122. http://dx.doi.org/10.1002/smj.557

Barrett, M. E. (1976). Financial Reporting Practices: Disclosure and Comprehensiveness in an International Setting. Journal of Accounting Research, 14, 10-26. http://dx.doi.org/10.2307/2490455

Benijts, T. (2010). A framework for comparing socially responsible investment markets: An analysis of the Dutch and Belgian retail markets. Business Ethics: A European Review, 19, 135-148. http://dx.doi.org/10.1111/j.1467-8608.2009.01578.x

Benson, K. L., Brailsford, T. J., \& Humphrey, J. E. (2006). Do Socially Responsible Fund Managers Really Invest Differently? Journal of Business Ethics, 65, 337-357. http://dx.doi.org/10.1007/s10551-006-0003-8

Breusch, T. S., \& Pagan, R. (1979). Simple Test for Heteroscedasticity and Random Coefficient Variation. Econometrica, 47, 1287-1294. http://dx.doi.org/10.2307/1911963

Capelle-Blancard, G., \& Monjon, S. (2014). The Performance of Socially Responsible Funds: Does the Screening Process Matter? European Financial Management, 20, 494-520. http://dx.doi.org/10.1111/j.1468-036X.2012.00643.x

Chen, J., Hong, H., Huang, M., \& Kubik, J. (2004). Does Fund Size Erode Mutual Fund Performance? The Role of Liquidity and Organization. American Economic Review, 94, 1276-1302. http://dx.doi.org/10.1257/0002828043052277 
Cooke, T. E. (1989). Voluntary Corporate Disclosure by Swedish Companies. Journal of International Financial Management and Accounting, 1, 171-195. http://dx.doi.org/10.1111/j.1467-646X.1989.tb00009.x

Cortez, M. C., Silva, F., \& Areal, N. (2012). Socially Responsible Investing in the Global Market: The Performance of US and European Funds. International Journal of Finance and Economics, 17, 254-271. http://dx.doi.org/10.1002/ijfe.454

Dubbink, W., Graafland, J., \& Van Liedekerke, L. (2008). CSR transparency and the Role of Intermediate Organization. Journal of Business Ethics, 82, 391-406. http://dx.doi.org/10.1007/s10551-008-9893-y

Elkington, J. (1997). Cannibals with Forks: the Triple Bottom Line of 21st Century Business. Oxford, UK: Capstone Publishing Limited.

Fulop, G., Hisrich, R. D., \& Szegedi, K. (2000). Business ethics and social responsibility in transition economies. Journal of Management Development, 19, 5-31. http://dx.doi.org/10.1108/02621710010308135

Harwood, I., Humby, S., \& Harwood, A. (2011). On the resilience of Corporate Social Responsibility. European Management Journal, 29, 283-290. http://dx.doi.org/10.1016/j.emj.2011.04.001

Hillman, A. J., Shropshire, C., \& Cannella Jr, A. A. (2007). Organizational predictors of women on corporate boards. Academy of Management Journal, 50, 941-952. http://dx.doi.org/10.5465/AMJ.2007.26279222

Humphrey, J. E. \& Lee, D. D. (2012). Australian socially responsible funds: Performance, risk and screening intensity. Journal of Business Ethics, 102, 519-535. http://dx.doi.org/10.1007/s10551-011-0836-7

Indro, D. C., Jiang, C. X., Hu, M. Y., \& Lee, W. Y. (1999). Mutual Fund Performance: Does Fund Size Matter? Financial Analysts Journal, 55, 74-87. http://dx.doi.org/10.2469/faj.v55.n3.2274

Kempf, A., \& Osthoff, P. (2007). The Effect of Socially Responsible Investing on Portfolio Performance. European Financial Management, 13, 908-922. http://dx.doi.org/10.1111/j.1468-036X.2007.00402.x

King, A. A., \& Lenox, M. J. (2001). Does it really pay to be green? Accounting for strategy selection in the relationship between environmental and financial performance. Journal of Industrial Ecology, 5, 105-116. http://dx.doi.org/10.1162/108819801753358526

Lee, D. D., Humphrey, J. E., Benson, K. L., \& Ahn, J. Y. K. (2010). Socially responsible investment fund performance: The impact of screening intensity. Accounting \& Finance, 50, 351-370. http://dx.doi.org/10.1111/j.1467-629X.2009.00336.x

Martì-Ballester, C. P. (2015). Investor reactions to socially responsible investment. Management Decision, 53, 571-604. http://dx.doi.org/10.1108/MD-04-2014-0207

Neter, J., Wasserman, W., \& Kutner, M. H. (1990). Applied linear statistical models (3rd ed.). Homewood, IL: Irwin.

Parnell, M., \& Seemann, K. (2005). Developing lifecycle models for sustainable investment in desert communities. Paper presented at the Proceedings of the Building for Diversity National Housing Conference 2005.

Pogutz, S., Russo, A., \& Migliavacca, P. O. (Eds.). (2009). Innovation, Markets and Sustainable Energy. The Challenge of Hydrogen and Fuel Cells. Cheltenham, UK: Edward Elgar.

Renneboog, L., Ter Horst, J., \& Zhang, C. (2008). The price of ethics and stakeholder governance: Evidence from socially responsible mutual funds. Journal of Corporate Finance, 14, 302-332. http://dx.doi.org/10.1016/j.jcorpfin.2008.03.009

Robinson, M., Kleffner, A., \& Bertels, S. (2011). Signaling Sustainability Leadership: Empirical Evidence of the value of DJSI Membership. Journal of Business Ethics, 101, 493-505. http://dx.doi.org/10.1007/s10551-011-0735-y

Russo, A., \& Perrini, F. (2006). The Real Cost of M\&A Advice. European Management Journal, 24(1), 49-58. http://dx.doi.org/10.1016/j.emj.2005.12.007

Russo, A., \& Mariani, M. (2013). Drawbacks of a delisting from a sustainability index: An empirical analysis. International Journal of Business Administration, 4(6), 29-58. http://dx.doi.org/ 10.5430/ijba.v4n6p29

Schueth, S. (2003). Socially Responsible Investing in the United States. Journal of Business Ethics, 43, 186-194.

SIF. (2012). Sustainable and Responsible Investing Trends in the United States: SIF Foundation.

Sparkes, R., \& Cowton, C. J. (2004). The Maturing of Socially Responsible Investment: A Review of the 
Developing Link with Corporate Social Responsibility. Journal of Business Ethics, 52, 45-57. http://dx.doi.org/10.1023/B:BUSI.0000033106.43260.99

Yu, L. (2014). Performance of Socially Responsible Mutual Funds. Global Journal of Business Research, 8, 9-17.

\section{Copyrights}

Copyright for this article is retained by the author(s), with first publication rights granted to the journal.

This is an open-access article distributed under the terms and conditions of the Creative Commons Attribution license (http://creativecommons.org/licenses/by/4.0/). 